www.jmscr.igmpublication.org Impact Factor 5.244

Index Copernicus Value: 83.27 ISSN (e)-2347-176x ISSN (p) 2455-0450 crossref DOI: _https://dx.doi.org/10.18535/jmscr/v4i12.24

\title{
The Effectiveness of Breathing Meditation and Progressive Relaxation Training in Reducing Pain and Stress among Young Nursing Professionals
}

\author{
Authors \\ M.Nagaraj ${ }^{1}$, B.Balachandar ${ }^{2}$ \\ ${ }^{1}$ Ph.D.-(F.T.) Research Scholar, Department of Psychology, Periyar University, Salem Tamilnadu \\ ${ }^{2}$ Clinical psychologist, Spastic centre, Trichy, Tamilnadu
}

\begin{abstract}
The aim of this study was to evaluate the quality of life of a group of nursing professionals who suffer from pain and stress and whether any relationship exists between time of evalution and severity of the problem. By simple random sampling method a sample of 30 nursing professionals was selected from a corporate hospital. Stress Level Questionnaire and Visual Analogue Pain Scale were used to measure the pain. Before data collection the purpose and benefits of Breathing exercise and Bernstein \& Borkovec's PRT were explained to the experimental group. After measuring the pre-training scores for pain and stress, the sample was trained to practice Breathing exercise and Bernstein and Borkovec's relaxation to induce relaxation. This training was done (15-20 minutes) twice daily for 12 days. The results revealed that the breathing exercise and Bernstein and Borkovec's progressive relaxation training, pain and stress of young nursing professionals are significantly reduced.
\end{abstract}

Keywords: Nursing Professionals, Pain and Stress, Quality of Life, Relaxation training.

\section{Introduction}

\section{Pain}

Pain is an uncomfortable feeling happen suddenly, due to some external stimuli like burning a finger, putting alcohol on a cut, and bumping the "funny bone". The International Association for the Study of Pain's widely used definition states: "Pain is an unpleasant sensory and emotional experience associated with actual or potential tissue damage". It has two types 1. 1. Acute pain: Is a mild pain, happen suddenly and last after a movement (or) week. For example, after trauma or surgery; in some rare environment, it can become chronic.

2. Chronic pain: Might have starts with a trauma, long time infections (or) past injuries. It persists over a longer period of time than acute pain and is needed for most medical management. Pain in the muscles and joints is often associated with stress. Musculoskeletal pain localized in the lower back, shoulders, and arms appears frequently to be unrelated to any disease and thus bear all indications of having psychological causes. (Harkness, McFarland, Silman, \& Macbeth, 2005).

\section{Gate Control Theory}

Ronald Melzack, a Canadian researcher who proposed the gate control theory with Patrick David Wall in 1965. The gate control theory of pain asserts that non-painful input closes the "gates" to painful input, which prevents pain sensation from traveling to the central nervous system. Therefore, stimulation by non-noxious input is able to suppress pain. 


\section{Physiology of pain}

Pain receptors, located in the skin and other tissues, are nerve fibers with endings that can be excited by three types of stimuli-mechanical, thermal, and chemical; some endings respond primarily to one type of stimulation, whereas other endings can detect all types. Chemical substances produced by the body that excite pain receptors include bradykinin, serotonin, and histamine.

The dual-phase experience of acute pain is mediated by two types of primary afferent nerve fibers that transmit electrical impulses .The A delta fibers are the larger and the most rapidly conducting of the two types, because of their thin myelin covering, and, therefore, they are associated with the sharp, well-localized pain that first occurs, and un myelinated $\mathrm{C}$ fibers respond to chemical, mechanical, and thermal stimuli and are associated with the lingering, poorly localized sensation that follows the first quick sensation of pain.

The peripheral nerves carries the Pain impulses in to spinal cord. It especially enter into the gray matter of the spinal cord. It is responsible for regulating and modulating the incoming impulses. Then the pain (fast and slow pain) enters into the brain in two different pathways. The fast pain enters the specific part of the brain cortex, and the slow pain distribute different area of the brain.

\section{Psychology of pain}

The perception of pain results from the brain's processing of new sensory input with existing memories and emotions, in the same way that other perceptions are produced. Childhood experiences, cultural attitudes, heredity, and gender are factors that contribute to the development of each individual's perception of and response to different. Blackburn-Munro (2001). reported that while approximately 30 percent of individuals who report pain are diagnosed with clinical depression,75 percent of patients diagnosed with depression also suffer from physical symptoms, including pain.

\section{Stress}

Stress is the emotional and physical response you experience. When you perceive an imbalance between demands placed on you and your resources at a time when coping is important. Robbins, (2001). defines stress a dynamic condition in which the individual is confronted with an opportunity constraint or demand related to what he or she desires and for which the outcomes is perceived to be both uncertain and important.

The symptoms of stress are mainly for physiologically increased pulse rate and blood pressure. And subjective symptoms are tiredness, fatigue and disturbed sleep pattern. PutzAnderson, (1988). defined cumulative trauma disorders as a collection of health problems that have three characteristics. First, they are cumulative; that is injuries develop over a long time as a result of repeated continuous exposure of a particular body part to stressors. Second, the repeated, continuous exposure to stressors leads to trauma of tissues and joints. Third WRMDs(Work Related Musculo skeletal Disorders) are physical ailments or abnormal conditions.

\section{Causes of Stress}

Some believe that stress is the mainly causes of the symptomology associated with many upper extremities (Halder, 1990). Smith, \& carayon Sainfort. (1989). have proposed a model of the work system for stress management that provides a useful framework for conceptualizing the work -related factors that contribute to WRMDs. The causes of the stress is mainly for the interaction between an individual's characteristics as a worker and the work environment is generally believed to result in stress (Tyson., Pongruengphant., \& Aggarawal, 2002). Most stressors can be grouped into one of three areas according to the Department of Consumer and Employment Protection.

- Stress caused by performing the job

- Stress occurring as a result of work relationships and finally; or 
- Stress resulting from the working conditions to which individuals are subjected.

\section{Need of the Study}

Nursing professionals commonly experience stress because after their completion of graduation they join job that is target oriented. They experience a sudden transition in career after their studies. Their sedentary life style, working overtime and night duties increase their stress. Nursing professionals in intensive care units displayed a higher prevalence of the perceived demand of noise compared to other wards within a hospital setting (Topf \& Dillan, 1994) not only does the perceived demand of noise interfere with speech perception and communication (Jones, 1999) but also, when it is prolonged, may lead to an increase in stress, signs of irritability, tension, anxiousness, anger, feelings of helplessness and hopelessness. Also the job demands adaptation to altered posture. This wrong posture may cause some group of muscles to over strain than some other group of muscles. This strain further aggravates their stress. Thus their occupational stress leads to pain in some muscle groups and this pain further intensifies their pain and stress. Meanwhile, Relaxation reduces Ischemic pain by normalizing blood flow to the muscles by making way for more oxygen to tissues. So the muscles get relaxation. The need of the study is to find whether there is any pain and stress among the young nursing professionals. The study also extends to find whether relaxation training is a useful way of managing such pain and stress.

\section{Problem and Hypotheses of the Study \\ Statement of the Problem}

This problem of this study is to find whether there is any pain and stress among nursing professionnals. Then the study extends to find whether relaxation training will be a useful way of managing such pain and stress. The study further aims to find whether there will be a reduction of pain and stress for both male and female and for different age groups (21 -35years).
Objectives of the Study

- To measure pain and stress for young nursing professionals.

- To find whether there is a significant reduction in pain and stress for young nursing professionals after the breathing exercise and progressive relaxation training.

\section{Hypotheses of the Study}

H1. There is a significant reduction in pain for young nursing professionals of 21-35 years age group after the breathing exercise and progressive relaxation training.

H2. There is a significant reduction in pain for young male nursing professionals after the breathing exercise and progressive relaxation training.

H3. There is a significant reduction in pain for young female nursing professionals after the breathing exercise and progressive relaxation training

H4. There is a significant reduction in stress for young nursing professionals of 21-35 years age group after the breathing exercise and progressive relaxation training.

H5. There is a significant reduction in stress for young male nursing professionals after the breathing exercise and progressive relaxation training.

H6. There is a significant reduction in stress for young female nursing professionals after the breathing exercise and progressive relaxation training.

\section{Method}

\section{Design}

The research design for this study was one group before - after design. In this design the group in the sample was trained by breathing meditation and Bernstein and Borkovec's progressive relaxation training to study their effect on stress and pain. Pre training and post training scores were taken from the group. 


\section{Sampling Method}

This study was conducted to find whether there would be a significant reduction in pain and stress after the breathing exercise and the progressive relaxation training. So it was planned to conduct the study among the nursing professionals of the age between 21-35 years. Since the population in this age group was so large and for the convenience of the researcher. The population of the study was taken from a private hospital in Trichy. Simple random sampling method of a sample of 30 nursing professionals was selected from the already selected 65 . No measures were taken to select the sample on the basis of sex. Both the sex was included. The variables of the study, is mainly for Breathing meditation and Relaxation training is independent variables and Pain \& Stress are dependent variables.

\section{Intervention}

A sample size of 30 was selected who satisfied the inclusion criteria. Their pre training score for the stress and pain was evaluated by using Stress Level Questionnaire (Dr. Latha sathish1998) and VAS respectively. Before data collection the purpose and benefits of Breathing exercise and Bernstein \& Borkovec"s PRT were explained to the group. The group was trained to practice Breathing exercise(5min) and Bernstein and Borkovec's relaxation training(15-20 minutes) twice daily for 12 days(6-session max).

Then the post training scores of pain and stress were recorded after the completion of the training regimen.

\section{Tools used}

Visual Analogue Pain Scale (VAS) The VAS is one of the most basic pain measurement tools. It consists of a 10 centimeter line. Bounded by terminal anchors. The $10 \mathrm{CM}$ line can be converted into a score between 0 and 10 , where 0 is no pain and 10 is severe pain. The sample has to mark their pain on the scale. The VAS is widely used because it is easily administered and requires little to no training. The test re'test reliability if the scale was found to be 0.99 and the concurrence validity was 0.86 .

Stress Level Questionnaire (Dr. Latha Sathish 1998). It consists of 52 items, mild stress (0-17), moderate (18-35) and severe stress (36-52). Here is a list of events /situation/ problems included. and you will have to mark 'yes' if you have experienced them and mark 'no' if you have not. The scale tried out on a sample of 80 subjects. The reliability was 0.86 and test reliability on a sample of 30 subjects was found to be 0.96 (p greater than 0.01 ). The content validity based on judges rating was 0.86 .

\section{Observation and Analysis \\ Data analysis}

The collected data was put in to the suitable analysis in order to verify the investigation of the study. Demographic characteristic of the data was presented through table's. The pre training and post training scores of pain and stress were analyzed by using mean and standard deviation, presented in the tables. The paired ' $\mathrm{t}$ ' test was used to find out the significant difference between the pre training and post training scores of pain and stress.

Table:1 Distribution of pain for the sample

\begin{tabular}{|l|l|l|r|l|}
\hline $\mathrm{N}$ & $\mathrm{M}_{\text {Pre-Test }}$ & $\mathrm{M}_{\text {post-test }}$ & $\mathrm{SD}$ & $\mathrm{t}$-value \\
\hline 30 & 4.05 & 1.85 & 0.852 & $14.95 * *$ \\
\hline$* * \mathrm{p}<0.01$
\end{tabular}

Thus the above table implies that the mean of the pre-training pain score was 4.05. After the intervention by relaxation training the mean of the post-training pain score was reduced to 1.85.The standard deviation was 0.852 . And the t- value was $14.95^{* *}$

Table:2 Distribution of pain for the male

\begin{tabular}{|l|l|l|l|l|}
\hline $\mathrm{N}$ & $\mathrm{M}_{\text {Pre-Test }}$ & $\mathrm{M}_{\text {post-test }}$ & $\mathrm{SD}$ & $\mathrm{t}$-value \\
\hline 18 & 3.92 & 1.83 & 0.835 & $10.72 * *$ \\
\hline
\end{tabular}

Thus the above table implies that the mean of the pre-training pain score was 3.92. After the 
intervention by relaxation training the mean of the post-training pain score was reduced to 1.83.The standard deviation was 0.835 . And the $\mathrm{t}$ - value was $10.72 * *$.

Table: 3 Distribution of pain for the female

\begin{tabular}{|l|l|l|l|l|}
\hline $\mathrm{N}$ & $\mathrm{M}_{\text {Pre-Test }}$ & $\mathrm{M}_{\text {post-test }}$ & $\mathrm{SD}$ & $\mathrm{t}$-value \\
\hline 12 & 4.25 & 1.92 & 0.785 & $10.31^{* *}$ \\
\hline
\end{tabular}

Thus the above table implies that the mean of the pre-training pain score was 4.25.After the intervenetion by relaxation training the mean of the post-training pain score was reduced to1.92.The standard deviation was 0.785 . And the $\mathrm{t}$ - value was $10.31^{* *}$.

Table :4 Distribution of stress for the sample

\begin{tabular}{|r|l|l|r|l|}
\hline $\mathrm{N}$ & $\mathrm{M}_{\text {Pre-Test }}$ & $\mathrm{M}_{\text {post-test }}$ & $\mathrm{SD}$ & $\mathrm{t}$-value \\
\hline 30 & 22.6 & 16.55 & 4.242 & $4.14 * *$ \\
\hline
\end{tabular}

Thus the above table implies that the mean of the pre-training Stress score was 22.6. After the intervention by relaxation training the mean of the post-training Stress score was reduced to 16.55 . The standard deviation was 4.242.And the t- value was $4.14 * *$.

Table: 5 Distribution of stress for the male

\begin{tabular}{|l|l|l|l|l|}
\hline $\mathrm{N}$ & $\mathrm{M}_{\text {Pre-Test }}$ & $\mathrm{M}_{\text {post-test }}$ & $\mathrm{SD}$ & $\mathrm{t}$-value \\
\hline 18 & 22.27 & 16.8 & 3.455 & $7.16^{* *}$ \\
\hline
\end{tabular}

Thus the above table implies that the mean of the pre-training stress score was 22.27. After the intervention by relaxation training the mean of the post-training stress score was reduced to 16.8. The standard deviation was 3.455 . And the $\mathrm{t}-$ value was $7.16^{* *}$.

Table: 6 Distribution of stress for the female

\begin{tabular}{|l|l|l|l|l|}
\hline $\mathrm{N}$ & $\mathrm{M}_{\text {Pre-Test }}$ & $\mathrm{M}_{\text {post-test }}$ & $\mathrm{SD}$ & $\mathrm{t}$-value \\
\hline 12 & 22.83 & 16.7 & 3.92 & $5.65 * *$ \\
\hline
\end{tabular}

Thus the above table implies that the mean of the pre-training stress score was 22.83. After the intervention by relaxation training the mean of the post-training stress score was reduced to 16.7.The standard deviation was 3.92. And the t- value was $5.65^{* *}$.

\section{Results and Discussion}

The difference between the means of pre training pain and stress scores and the means of post training pain and stress scores of the young nursing professionals of the age group 21-35, Male and Female shows a significant reduction of their pain and stress scores. So the hypothesis $\mathrm{H} 1$ to $\mathrm{H}$ 6-there is no significant reduction in pain and stress of the young nursing professionals of the age group between 21-35, Male and Female after the breathing exercise and the progressive relaxation training, is not accepted. Therefore the result concludes that, there is significant reduction in pain and stress of the young nursing professionals of the age group between 21-35, Male and Female years, after the breathing exercise and the progressive relaxation training.

\section{Conclusions}

To conclude in this study that, there is a significant reduction in pain and stress of the young nursing professionals of the age group between 21-35, male and female after the breathing exercise and progressive relaxation training.

\section{Implications}

As regards, in many organizations like private and government sectors the employees have lot of workloads. So easily they can get stress, anxiety and depression. In industrial and organizational psychologist could design and develop training modules which may foster work related flow by enhancing self stimulation and intrinsic motivation of the employees. However in recent days many organizations are already providing counseling and relaxation training to employees at all the levels. So it help them to overcome their stress and perform better. While it may be financially unviable for all organizations to recruit counselors, it will be better to explore the possibility of retaining the services of professional counselors. 


\section{References}

1. Arcusa, A. (2007). A randomized trial of the effect of training in relaxation and guided imagery techniques in improving psychological and quality-of-life indices for gynecologic and breast brachytherapy patients. Psycho oncology. (2nd edition).

2. Al-aameri; \&Al-fawzan, (1998). Nurses strategies for coping with job stress. Saudi Medical Journal.

3. Anderson, VL; Levinson, EM; Barker, W; \& kiewra, KR. (1999). The effects of meditation on teacher perceived occupational stress, state and trait anxiety, and burnout. School Psych Quart.

4. Astin, J.A. (1997). Stress reduction through mindfulness meditation. Psychotherapy (2nd edition)

5. Baron, R.M, (2003). A nursing crisis. Nursing update.

6. Burns, N; \& Susan, K.Grove. (2001). The practice of nursing research. $\left(4^{\text {th }}\right.$ edition.).Philadelphia: w.b. Saunders Company.

7. Callaghan, P; Tak-ying, S.A; \& Wyatt, P.A. (2000). Factors related to stress and coping among Chinese nurses in hong kong. ( $2^{\text {nd }}$ edition.). journal for advance nursing. Hong Kong.

8. Cottrell, S.(2001). Occupational stress and job satisfaction in mental health nursing: focused interventions through evidencebased assessment. Journal of psychiatric and mental health nursing. Blackwell science ltd: London.

9. Campbell J.N; \& Meyer RA. (2006). Mechanisms of neuropathic pain.

10. Carrington, P; Collings, G.H; \&.Benson, H et al. (1980). The use of meditation relaxation techniques for the management of stress in a working population. Journal of occupational medicine.
11. Gregory.S.kolt; \& Mark.B.anderson. (2004). Psychology in the physical and manual therapies. $1^{\text {st }}$ edition.

12. International association for the study of pain (1986). Subcommittee on taxonomy. Classification of chronic pain syndromes and definitions of pain terms. Pain. $2^{\text {nd }}$ edition.

13. Jacobson, E. (1938). Progressive relaxation. ( $1^{\text {st }}$ edition) Chicago: university of Chicago press.

14. Jacobs, G.D. (2001). The Physiology of Mind-Body Interactions: The stress response and the relaxation response. Journal of alternative and complementary medicine.

15. Jacobson, P.L; \& Mann, J.D.(2004). The valid informed consent-treatment contract in chronic non-cancer pain: its role in reducing barriers to effective pain management. Comprehensive therapy.

16. Kothari, C.R. Research methodology. ( $2^{\text {nd }}$ edition).

17. Kabat-zinn, J. (1982). An out-patient program in behavioral medicine for chronic pain patients based on the practice of mindfulness meditation: theoretical considerations and preliminary results. gen. hosp. psychiatry.

18. Wang, L; \& LI Chen, (2008). Occupational stress among hospital nurses. Journal of advanced nursing ( $2^{\text {nd }}$ edition). China.

19. Miller, J.J; Fletcher, K; \& Kabat-zinn, J. (1995).Three-year follow-up and clinical implications of a mindfulness meditationbased stress reduction intervention in the treatment of anxiety disorders. gen. hosp. psychiatry.

20. Susan B.O'Sullivan; \& Schmitz, TJ. Physical Rehabilitation. ( $5^{\text {th }}$ edition). http : // en.wikipedia. org 